\title{
Analysis of drying stresses in green-glued plywood of Bete (Mansonia Altissima) specie
}

\author{
Valentin Makomra ${ }^{1,3^{*}}$ (D) René Oum Lissouck ${ }^{2,3}$, Régis Pommier ${ }^{1}$, Anh Phan Ngoc ${ }^{1}$, Denys Breysse ${ }^{1}$, \\ Louis Denaud ${ }^{4}$ and Louis Max Ayina Ohandja ${ }^{2}$
}

\begin{abstract}
The wood veneer dried artificially before gluing for the manufacture of plywood generally suffers several damages (cracks, deformations), decreasing the competitiveness of the process and limiting the use of nervous species of wood. The proposed solution is to glue them at the green state. However, during the drying process, superficial and internal cracks are observed. These cracks appear when stresses due to the anisotropic shrinkage of the plywood exceed the mechanical strength of the wood material. In the present study, the response of a 3-ply plywood of Bete (Mansonia altissima) glued at the green state is simulated in order to evaluate these stresses and deformations during drying using a finite element method program. The numerical results and associated experimental data make it possible to better analyze and understand the mechanical behavior of the plywood during drying in order to look for reliable plywood through new process.
\end{abstract}

Keywords: Plywood, Green-glued plywood, Drying stresses, Finite element

\section{Introduction}

Plywood factories have been using wood veneer obtained by unrolling some species for a long time. The artificial drying of these wood veneers, the only industrial process, leads to a certain number of incidents that may occur during the process. Some defects are visible (superficial cracks and deformations) while others may be non-visible (internal cracks). Nevertheless, they are susceptible to induce future failure [1]. To provide solutions, several works have developed products glued at the green state $[2,3]$, and in particular plywood panels using different technologies [4-7]. At the industrial level, this technique may allow some energy savings and reduce the degradation of the material integrity of veneers during handling. Lavalette [8] has shown that the product from the vacuum drying of green-glued plywood processing, meets the standard requirements for shear stress according to EN 314-1 [9]. But, she showed some superficial cracks

\footnotetext{
*Correspondence: makomra@yahoo.fr

${ }^{1}$ Univ. Bordeaux, I2M, UMR 5295, 351 cours de la Libération,

33400 Talence, France

Full list of author information is available at the end of the article
}

probably due to the stresses induced by the gradient of moisture and anisotropic shrinkage.

To forecast these internal stresses and strains, which is a prerequisite to design the products, it is difficult to build an experimental design without the use of numerical simulations. The numerical model of the hydro-mechanical behavior during the drying of solid wood products has been the subject of several studies on sawn timber products $[10,11]$ and crossed lamellae panels [12]. These questions are still to be answered for plywood, especially as the thickness of the wood veneer and the method of their production are different from those of the products mentioned above. Thus, finite element simulations can be performed to study how the internal structure and properties of the material affect the plywood shape stability.

The objective of the study is to determine the drying stresses in green-glued plywood by FEM analysis (Cast3M Finite Element Software). To perform an accurate simulation, it is essential to have a sufficiently detailed description of the properties of the wood. The mechano-sorption, the elastic, visco-elastic behaviors are implemented in Cast3M finite element software during drying. For this purpose, experimental drying tests 


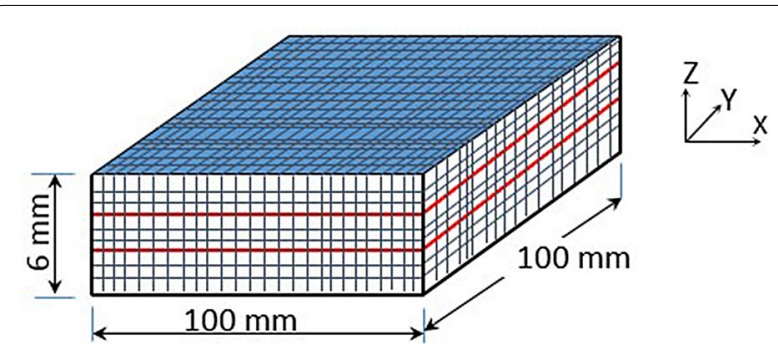

Fig. 1 Geometry and mesh of the plywood sample

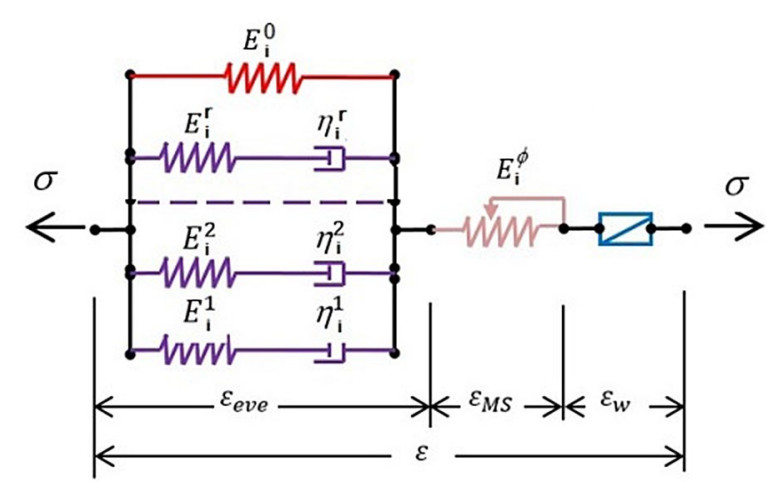

Fig. 2 Illustration of the rheological Maxwell model for a direction i of the wood. With $i \in\{L, T, R\}$, the orthotropic direction of wood; $E_{i}^{\mu}$, the elastic modulus of the branch $\mu \in\{1,2, \ldots, r\}$ along the direction $i_{i} \eta_{i}$, the viscosity in direction $i_{i} E_{i}^{0}$, the real modulus of wood in direction $i ; E_{i}^{\varnothing}$, the mechano-sorptive modulus in the direction $i$

of plywood consisting of three plies of size $100 \times 100 \times 6$ $\mathrm{mm}^{3}$ (Fig. 1) permit to follow their deformation. The hydro-mechanical test setup for the veneers have been carried out and the results used in the numerical drying tests. They have made it possible to reproduce the experimental behavior (deformations, drying kinetics, etc.) and to provide estimates of the internal stresses in plywood.

\section{Methods and experiments}

\section{Numerical model}

Several models of wood behaviors were offered during those last years. The models of stress/deformation were developed, and most of them assumed that mechanical properties change during the drying. They provided a better knowledge of the mechanical behavior and may aid to improve the quality of the wood during drying [13, 14]. The rheological model implemented in the numerical approach is briefly described below. The constitutive equation given by Eq. (1) expresses the total strain $\Delta \varepsilon$ as a sum of three separate strains, describing the fundamental behaviors of wood. It is illustrated by the Maxwell figure of $r$ branches (Fig. 2).

$$
\Delta \varepsilon=\Delta \varepsilon_{\text {eve }}+\Delta \varepsilon_{m s}+\Delta \varepsilon_{w},
$$

where $\Delta \varepsilon_{\mathrm{w}}$ is the free shrinkage/swelling that occurs when the water content is below the fiber saturation point $\left(W_{\mathrm{fsp}}\right)$. It is defined as:

$$
\Delta \varepsilon_{w}=\alpha \Delta w
$$

with $\alpha$ as the shrinkage/swelling coefficient (independent of moisture) and $\Delta w$ is the variation of moisture content; $\Delta \varepsilon_{\text {eve }}$ is the elastic and visco-elastic strain defined by using the chain model of Maxwell as follows: for

$$
\begin{gathered}
\Delta t, \Delta \varepsilon_{\text {eve }}=[\tilde{K}]^{-1} \Delta \sigma-[\tilde{K}]^{-1} \sigma^{h i s}(t), \\
\text { with } \tilde{K}=E^{0}(w)\left[1+\sum_{\mu=1}^{r} \gamma_{\mu}\left(\frac{1-e^{-\alpha_{\mu} \Delta t}}{\alpha_{\mu} \Delta t}\right)\right], \quad \text { where } \\
\gamma_{\mu}=\frac{E^{0}(w)}{E^{\mu}} \text { and } \alpha_{\mu}=\frac{E^{\mu}}{\eta^{\mu}}\left(\text { unitins }^{-1}\right), \text { and } \sigma^{h i s}(t)=\sum_{\mu=1}^{r}
\end{gathered}
$$
$\left(1-e^{-\alpha_{\mu} \Delta t}\right) \sigma^{\mu}(t)$, and $\tilde{K}$ is the fictious rigidity. It depends on the length of the time step, the parameters of Maxwell; $E^{0}(w)$ is the elastic modulus at the beginning of the increment. It depends on moisture content w; $E^{\mu}$ and $\eta^{\mu}$ are, respectively, the elastic modulus and the viscosity of the branch $\mu . \sigma^{\text {his }}(t)$ is the term of the history. Its depends on the length of the step time $\Delta t$, the state of the deformation $\varepsilon(t)$ and the recent values gained by the internal stress $\sigma^{\mu}(t)$ at the beginning of the increment. $\Delta \varepsilon_{\mathrm{ms}}$ is the mechano-sorptive deformation, and depends linearly on the stress and the variation of the water content. This definition leads to the formulation of the following expression of deformation which does not depend on the previous ones [10]:

$$
\Delta \varepsilon_{m s}=m \sigma \Delta w
$$

where $\mathrm{m}$ is the compliance of mechano-sorptive creep.

From Eq. (1), the total formulation then can be written:

$$
\Delta \varepsilon=\alpha \Delta w+[\tilde{K}]^{-1} \Delta \sigma-[\tilde{K}]^{-1} \sigma^{h i s}(t)+m \sigma \Delta w
$$

\section{Identification and experimental determination of input parameters of the model}

In order to validate the numerical simulation by experiments, we choose the Bete specie as a reference. It permits to describe and identify the input parameters of the model like the isothermal desorption, coefficients of diffusion and exchange, the test boundary condition and material data. 


\section{Description of Bete specie}

Bete (Mansonia altissima) is one of the most abundant hardwood species from the Congo Basin forest [15]. The color of the wood is brown and the grain is straight. The wood can be used in frame, parquet and paneling. According to the CIRAD (Agricultural Research Centre for International Development, in French) technological database [16], the density at $12 \%$ moisture content varies from 0.59 to 0.72 . The average elastic modulus in the longitudinal direction (MOE) is $13,600 \mathrm{MPa}$, with a standard deviation of $1124 \mathrm{MPa}$. The mean value of the modulus of rupture in bending (MOR) is $110 \mathrm{MPa}$, with a standard deviation of $10 \mathrm{MPa}$. The compressive rupture stress is $60 \mathrm{MPa}$, with a variation coefficient of $10 \%$. The average $W_{\text {fsp }}$ value is $28 \%$ [15]. The tangential and radial shrinkage coefficients vary, respectively, from $0.241 \%$ to $0.286 \%$ and from $0.15 \%$ to $0.178 \%$.

\section{Determination of the isothermal desorption of Bete specie}

Ten samples in green state (saturated) of size $20 \times 20 \times 2$ $\mathrm{mm}^{3}$ were placed in a climatic chamber at constant temperature of $40{ }^{\circ} \mathrm{C}$. Then the relative humidity $(\mathrm{RH})$ inside the device was varied from 95 to $10 \%$. For each $\mathrm{RH}$ value, the samples remained in the oven until their masses stabilized. A given mass was considered as stabilized in this study when its relative variation was equal or less than 0,001 . Knowing the saturated and anhydrous mass values (obtained at $105{ }^{\circ} \mathrm{C}$ ), we deduced the water content $W_{c}$, and the couple $\left(\mathrm{RH}, W_{\mathrm{c}}\right)$ provided each point of the isotherm desorption curve.

\section{Determination of the shrinkage coefficient of Bete specie}

The full shrinkage radial and tangential of Bete specie were determined experimentally by using 5 samples in green state (saturated) of size $20 \times 20 \times 2 \mathrm{~mm}^{3}$. We assumed that the coefficients are constants. They were placed in an oven at constant temperature of $40{ }^{\circ} \mathrm{C}$ and humidity of $90 \%$ until their mass stabilized in order to have the $W_{\mathrm{fsp}}$ value. The tangential and radial dimensions were measured. The same sizes were also measured for the same specimens in anhydrous state. From those dimensions, we deduced the radial and tangential shrinkage coefficients.

\section{Determination of the density of the Bete species}

To determine the density, the same specimens for the determination of shrinkage coefficients were used. We assume that the longitudinal shrinkage of the specimen is neglected. Knowing the dimension and the mass, we deduced the density $\rho_{\mathrm{w}}$ at $0 \%$ of $W_{\mathrm{c}}$ and by the relation $\rho_{\mathrm{w}}(W \%)=\rho_{\mathrm{w}}(0 \%)(1+W / 100)[22]$, the density versus the $W_{\mathrm{c}}$.

\section{Determination of elastic properties of the Bete species}

For the determination of elastic properties of Bete plywood, the tensile tests were carried out on specimen obtained after unrolling and conditioning at a temperature of $40{ }^{\circ} \mathrm{C}$ and a relative humidity of $70 \%$ (which corresponds to an average moisture content of about $12 \%$ at the hygroscopic equilibrium). The tensile tests are inspired by the standard NF EN 326-1 [17]. However, a different specimen geometry was used because preliminary tests showed that the rupture occurred in the jaws of the standard specimen. More precisely, we used a "dumbbell" specimen [8], reinforced by wooden heels at the jaws, in order to ensure the rupture in the useful part of the sample. It was cut, respectively, in the parallel and perpendicular directions of the fibers in order to obtain the elasticity modulus in those two principal directions.

\section{Fabrication of 3-ply plywood}

About 2-mm-thick Mansonia altissima rotary cut veneer (from the production forest of Cameroon) was used for plywood manufacture. Wood plies were selected defect free, with a regular slope of grain in order to avoid their effect on test results. They were cut to the panel dimensions $\left(600 \times 600 \times 2 \mathrm{~mm}^{3}\right)$ and initially stored in a conditioning chamber at $4{ }^{\circ} \mathrm{C}$ to keep their moisture content beyond the $W_{\text {fsp }}$. Then the wood plies were taken off the chamber and glued. The adhesive used was a one-component polyurethane (ref: Collano RP 2554) with a viscosity of $1000 \mathrm{mPa} / \mathrm{s}$ at $20^{\circ} \mathrm{C}$, developed from the adhesive patented for green plywood gluing [18]. It was spread on the plies by using a notched squeegee so that the glue was evenly distributed. 3-ply plywood panels were manufactured by using the vacuum process technique $[7,8]$. The plies were oriented according to two arrangements options. The first one was antisymmetric ($\left.15^{\circ} / 0^{\circ} \%+15^{\circ}\right)$. It was considered in order to validate the numerical model of drying plywood. The second one was symmetric $\left(0^{\circ} / 90^{\circ} / 0^{\circ}\right)$ which represents the conventional plywood. The panels were placed in a vacuum dryer set to $150 \mathrm{mbar}$ to ensure the bonding and equipped with a device (microprocessor) indicating their average moisture content (about 55\%). The average moisture content of the panels when they were removed from the drier was $35 \%$. The panels were cut according to the dimensions of the samples (section of $100 \times 100 \mathrm{~mm}^{2}$ ) and placed in an oven where the relative humidity and the temperature were, respectively, $95 \%$ and $10{ }^{\circ} \mathrm{C}$. Thus, their moisture content could be close to the $W_{\text {fsp }}$. We remind that the $W_{\text {fsp }}$ average value, according to the literature is $28 \%$.

\section{Determination of coefficients of diffusion and exchange}

The relationship between the diffusion coefficient $K_{\mathrm{D}}$ and the water content in the wood is far from being 
definitively established. The $K_{\mathrm{D}}$ values found in the literature depend on wood species and widely vary. The transfer of water in the wood is hindered by two resistances: an internal one which can be described by the diffusion coefficient $K_{\mathrm{D}}$, and a second one which is developed at the interface between the specimen and the external environment, which can be described by the surface exchange coefficient $K_{\mathrm{C}}$ [19-21]. The boundary conditions associated with the mass diffusion equation are literally written in the unidirectional framework by the following system of equations as (Eq. 6):

$$
\begin{cases}\frac{\partial w}{\partial t}=\frac{\partial w}{\partial z}\left(K_{D}(w) \frac{\partial w}{\partial z}\right) & \text { with } 0<z<a \\ w=w_{\text {ini }} & \text { for } z \in[0, a] \text { at } t=0 \\ K_{D}(w) \frac{\partial w}{\partial z}=K_{C}\left(w_{\text {surf }}-w_{e q}\right)=Q_{m} ; & (z=a, t>0)\end{cases}
$$

with $K_{\mathrm{D}}$ as the coefficient of diffusion of the material; $W$, the moisture content in the material; $W_{\text {surf }}$, the moisture content on the surface of the material; $W_{\text {ini }}$, the initial moisture content in the material (at the beginning of drying); $W_{\text {eq }}$, the equivalent moisture content to the relative humidity of the study environment; $K_{\mathrm{C}}$, the exchange coefficient between the material and the ambient environment; $a$, the specimen thickness; $t$, the time; and $Q_{m}$, the flux of surface water content.

For experimental determination, 10 green-glued plywood specimens were placed in a climatic chamber in which the air relative humidity and the temperature were, respectively, $50 \%$ and $40{ }^{\circ} \mathrm{C}$. In such conditions, the moisture content at the hygroscopic equilibrium was $10 \%$. These parameters correspond to a desorption of the specimens. The four lateral faces (RT and RL planes) of each sample were insulated with an EPI (emulsion polymer isocyanate) adhesive of a Kleiberit brand in order to impose the diffusion in the radial direction of the sample (Fig. 3).

At each hour, the samples were weighed. The anhydrous masses were obtained after setting the samples in the oven at $105^{\circ} \mathrm{C}$ till their mass stopped varying. Then, we deduced the evolution of the moisture content with the time in order to determine the diffusion and exchange coefficients.

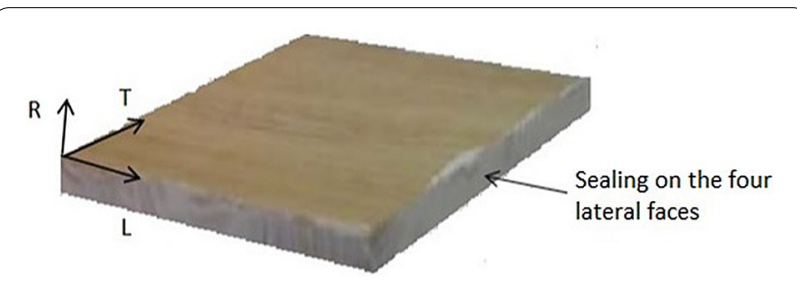

Fig. 3 Sample of sealing specimen

\section{Validation of the numerical model}

In order to validate the numerical results, the configuration of plywood chosen was arranged with asymmetrical ring orientations (longitudinal direction). The first and third plies are inclined by $\pm 15^{\circ}$ about the direction of the fiber as indicated in Fig. 4. The process was conducted by following to steps.

In the first step, five green-glued plywood specimens with an initial average moisture content of approximately $32 \%$ were placed in a drying oven with the diffusion and theoretical mechanical boundary conditions mentioned in Fig. 5. These mechanical boundary conditions corresponded to simple supports experimentally. During the experiment, the specimens were placed on a grilling of the dryer, without holding, allowing them to perform free flexural deformation and to avoid any generation of external stress. The displacements $U_{\mathrm{z}}$ of the point $\mathrm{P}_{1}$ of the plywood (Fig. 5) of each sample were measured each hour using a digital caliper.

In the second step, the fitting between experimental and numerical values was realized by minimizing the quadratic gap between the numerical and experimental displacements of the point $\mathrm{P}_{1}$ according to two scenarios. The first one did not take into account the visco-elastic behavior of the plywood. In the second one, that behavior was considered.

The material parameters used for the numerical simulation are listed in Table 1 and are representative of the wood veneers of the Bete species.
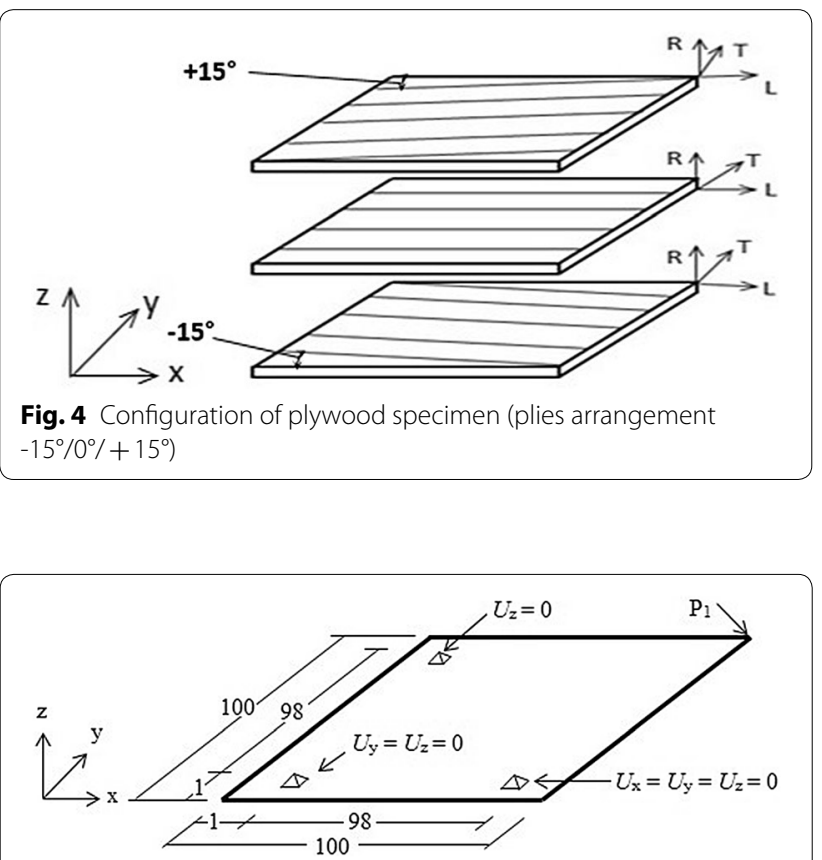

Fig. 5 Boundary conditions on the plywood 
The following assumptions were considered:

a- The influence of the moisture content $W(\%)$ on the elastic properties specified in Table 1 and the density of the woods was taken into account by using linear corrections given by Guitard [22] on the modulus of elasticity (Eq. 7) and density (Eq. 8):

$$
\mathrm{S}_{\mathrm{ij}}^{-1}(\mathrm{~W})=\mathrm{S}_{\mathrm{ij}}^{-1}(12 \%)\left[1-\mathrm{C}_{\mathrm{ij}}(\mathrm{W}-12)\right]
$$

with $C_{\mathrm{ij}}$ constant coefficients and $\mathrm{S}_{\mathrm{ij}}^{-1}(\mathrm{~W})$ the elastic properties.

$$
\rho_{\mathrm{W}(\mathrm{W} \%)}=\rho_{\mathrm{W}(0 \%)}(1+W / 100)
$$

$\mathrm{S}_{\mathrm{ij}}^{-1}(\mathrm{~W})$ are defined as follows (Eq. 9):

$$
\begin{aligned}
S_{11}^{-1} & =E_{R} ; S_{22}^{-1}=E_{T} ; S_{33}^{-1}=E_{L} ; S_{44}^{-1} \\
& =G_{L T} ; S_{55}^{-1}=G_{L R} ; S_{66}^{-1}=G_{R T}
\end{aligned}
$$

b- The shrinkage coefficients were constant during drying.

c- We assumed that the viscosity parameters of the Maxwell model with three branches $(n=3)$ are the same for the direction of the plywood.

The validated numerical model permits to quantify and predict the fields of deformations and stresses according to two configurations: the first one was asymmetrical and the second was conventional (Fig. 6). The main interest of the asymmetrical configuration was the comparison of experimental and numerical results. In the second configuration, veneers are arranged orthogonally (Fig. 7) and the main purpose was the comparison of drying stresses and the ultimate strength of the veneers.

\section{Results and discussion}

\section{Isothermal desorption of the Bete}

Figure 7 presents the plot of the equilibrium moisture content versus the relative humidity of the Bete species. Experimental results were fitted according to the Henderson model [24] (Eq. 10):

$$
H R=1-\exp \left[-\mathrm{A}(\mathrm{T}+\mathrm{B})\left(\mathrm{W}_{\mathrm{eq}}\right)^{\mathrm{C}}\right] .
$$

The estimated values of $A, B$ and $C$ at the end of the fitting process were, respectively, $0.14,100$ and 1.9. $T$ is the temperature in Kelvin degree.

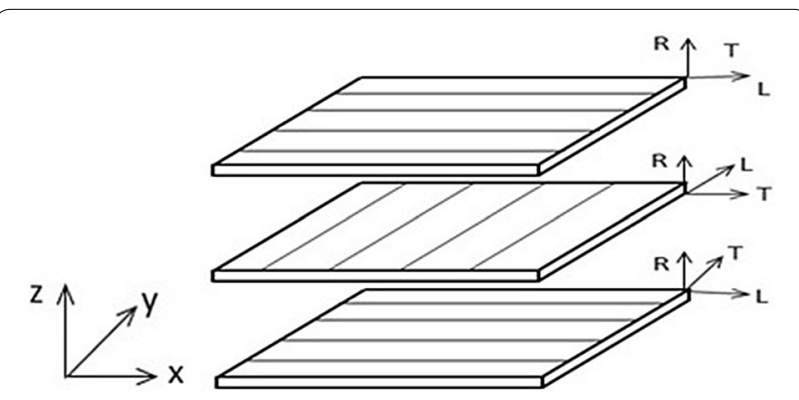

Fig. 6 Configuration of plywood

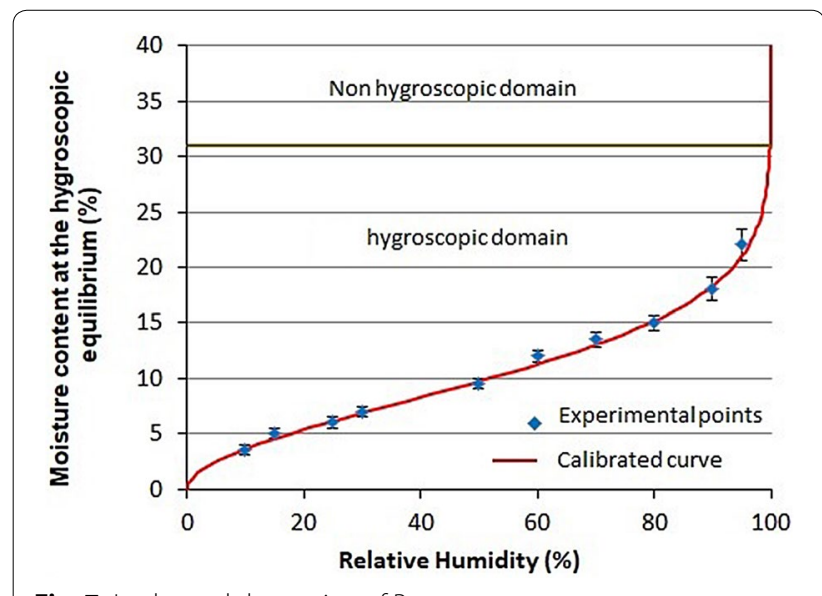

Fig. 7 Isothermal desorption of Bete

The $W_{\text {fsp }}$ value, corresponding to the limit of nonhygroscopic domain, was 32\% (Fig. 7).

\section{Shrinkage coefficient of Bete specie}

The experimental result of tangential and radial shrinkage is given in Table 2. We notice that the value of the tangential shrinkage is bigger than the one found in the literature. On the other hand, we have almost the same result of radial shrinkage as in the literature.

\section{Volumic mass and density of specie of Bete}

The average density value obtained experimentally in anhydrous conditions is 0.59 , with a standard deviation of 0.05 . By using Eq. 8, the value at $12 \%$ practically showed no variation (from 0.655 to 0.666 ). Such results correspond to the literature mean value of 0.66 (volumic mass of $660 \mathrm{~kg} / \mathrm{m}^{3}$ ).

\section{Elastic properties of plywood}

The results of tensile tests of the Bete plies are shown in Table 3.

The results show that the elastic modulus and the failure strength of the samples in the longitudinal direction 
Table 1 Material parameters used

\begin{tabular}{|c|c|c|c|c|c|c|}
\hline \multirow{2}{*}{$\frac{\mathbf{N}^{\circ}}{1}$} & \multirow{2}{*}{$\begin{array}{l}\text { Designation } \\
\text { Elastic properties (12\%) }\end{array}$} & \multicolumn{4}{|c|}{ Parameters along orthotropic directions } & \multirow{2}{*}{$\begin{array}{l}\text { Observations } \\
E_{L} \text { and } E_{T} \text { were determined experimen- } \\
\text { tally. The other elastic properties were } \\
\text { obtained from the literature }[16,22]\end{array}$} \\
\hline & & $\begin{array}{l}E_{L}(\mathrm{MPa}) \\
G_{\mathrm{LT}}(\mathrm{MPa}) \\
V_{\mathrm{LT}}=0.46\end{array}$ & $\begin{array}{l}E_{T}(\mathrm{MPa}) \\
\mathrm{G}_{\mathrm{TR}}(\mathrm{MPa}) \\
v_{\mathrm{TR}}=0.39\end{array}$ & & $\begin{array}{l}E_{R}=1846 \mathrm{MPa} \\
G_{\mathrm{LR}}(\mathrm{MPa}) \\
v_{\mathrm{LR}}=0.39\end{array}$ & \\
\hline 2 & Failure strengths & $\sigma_{\mathrm{RL}}(\mathrm{MPa})$ & $\sigma_{R T}(\mathrm{MPa})$ & & & $\sigma_{\mathrm{RL}}$ and $\sigma_{\mathrm{RT}}$ were obtained experimentally \\
\hline 3 & Total shrinkage coefficient & $a_{L}=0.001$ & $a_{T}(\%)$ & & $a_{R}(\%)$ & $\begin{array}{l}a_{T} \text { and } a_{R} \text { were determined experimen- } \\
\text { tally. } a_{L} \text { was given by the literature }\end{array}$ \\
\hline 4 & Density of wood (Bete) (12\%) & & & & & $\begin{array}{l}\text { This value was determined experimen- } \\
\text { tally }\end{array}$ \\
\hline \multirow[t]{2}{*}{5} & \multirow[t]{2}{*}{$\begin{array}{l}\text { Compliances of mechano-sorptive } \\
\text { creep }\left(\mathrm{MPa}^{-1}\right)\end{array}$} & $\begin{array}{l}m_{L}=0.110^{-3} \\
m_{\mathrm{LT}}=0.008 \\
\mu_{\mathrm{LT}}=0\end{array}$ & $\begin{array}{l}m_{T}=0.15 \\
m_{\mathrm{RT}}=0.8 \\
\mu_{\mathrm{RT}}=1\end{array}$ & & $\begin{array}{l}m_{R}=0.2 \\
m_{\llcorner R}=0.00810^{-3} \\
\mu\llcorner R=0\end{array}$ & \multirow{2}{*}{$\begin{array}{l}\text { Obtained in the literature }[13,23] \\
m_{i}=\text { compliance in the direction } \mathrm{i} \\
m_{\mathrm{ij}}=\text { compliance in the plan ij } \\
\text { with } i, j \in\{\mathrm{L}, \mathrm{T}, \mathrm{R}\} \text { : direction of wood }\end{array}$} \\
\hline & & 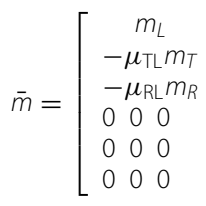 & $\begin{array}{cc}-\mu_{\mathrm{LT}} m_{L} & -\mu_{\mathrm{LR}} m_{L} \\
m_{T} & -\mu \mathrm{TRR}_{\mathrm{R}} m_{T} \\
-\mu_{\mathrm{RT} T} m_{r} & m_{R} \\
& \\
& \end{array}$ & $\begin{array}{ll}0 & 0 \\
0 & 0 \\
0 & 0 \\
m_{T R} \\
0 \\
0\end{array}$ & 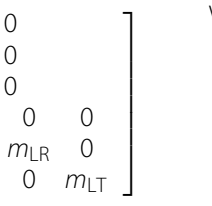 & \\
\hline 6 & $\begin{array}{l}\text { Diffusion }\left(K_{D}\right) \text { and exchange coefficients } \\
\left(K_{C}\right)\end{array}$ & $\begin{array}{l}K_{D}\left(\mathrm{~m}^{2} / \mathrm{s}\right) \\
K_{C}(\mathrm{~m} / \mathrm{s})\end{array}$ & & & & $\begin{array}{l}\text { These parameters were determined } \\
\text { experimentally }\end{array}$ \\
\hline \multirow[t]{2}{*}{7} & Viscosity parameters & $\begin{array}{l}\gamma_{1}^{\prime} \\
\gamma_{2}^{\prime} \\
\gamma_{3}^{\prime} \\
\left(\alpha_{1}^{\prime}\right)^{-1} \text { (hours) } \\
\left(\alpha_{2}^{-1}\right)^{-1} \text { (hours) } \\
\left(\alpha_{3}^{\dagger}\right)^{-1} \text { (hours) }\end{array}$ & $\begin{array}{l}\gamma_{\mu}^{\prime}=\gamma_{\mu}^{t}=\gamma_{\mu}^{r} \\
\alpha_{\mu}^{\prime}=\alpha_{\mu}^{t}=\alpha_{\mu}^{r}\end{array}$ & & $\begin{array}{l}\text { with } \gamma_{\mu}^{i}=\frac{E_{0}^{i}}{E_{\mu}^{i}} \text { and } \\
\alpha_{\mu}^{i}=\frac{E_{\mu}^{i}}{\left(s^{-1}\right)}\end{array}$ & 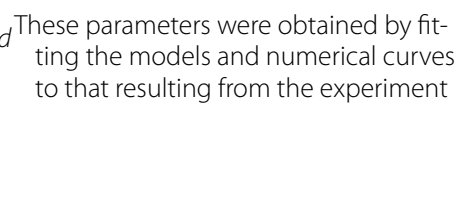 \\
\hline & & With $\epsilon\{1,2,3\}$ : & er of bra & & 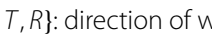 & \\
\hline
\end{tabular}

are close to those of the solid wood obtained from the reference [16]. In the direction perpendicular to the fibers, the average elastic modulus is much lower than the module found in the literature. This can be explained by the presence of peeling slots.

\section{Diffusion and exchange coefficients}

Figure 8 shows an exponential decrease of the moisture content with the drying time. It was therefore possible to determine the expression of diffusion coefficient $K_{\mathrm{D}}$ as an exponential function of the moisture content. Similar trends are available in the literature [19-21]. By fitting the experimental curve of the evolution of the moisture content (Fig. 8), we found the analytical expression of the diffusion coefficient (Eq. 11). We remind that the relative humidity and the temperature conditions are, respectively, $50 \%$ and $40{ }^{\circ} \mathrm{C}$ :

$$
K_{D}=K_{0} \exp \left(K_{0 w} w\right)
$$

with $K_{0}$, as the constant diffusion $\left(5,8410^{-10} \mathrm{~m}^{2} / \mathrm{s}\right) ; K_{0 \mathrm{w}}$, as the constant coefficient $(1,97)$, and $w$, the moisture content (\%) (Table 4).

The value of the coefficient $K_{\mathrm{C}}$ and the expression of $K_{\mathrm{D}}$ are presented in Table 4.

In the literature, several authors conducted investigations concerning the mass transfer properties of wood
[25, 26]. Concerning central Africa tropical woods, some results on species like sapelli (Entandrophragma cylindricum) and sipo (Entandrophragma utile) are available [27-29]. Such timber species present similar technological properties with Bete [30]. For instance, their mean density varies from 0.62 to 0.66 . Explicit results concerning the diffusion coefficients were determined by Nsouandelé [29]. At a temperature of $40^{\circ} \mathrm{C}$ and a $\mathrm{RH}$ of

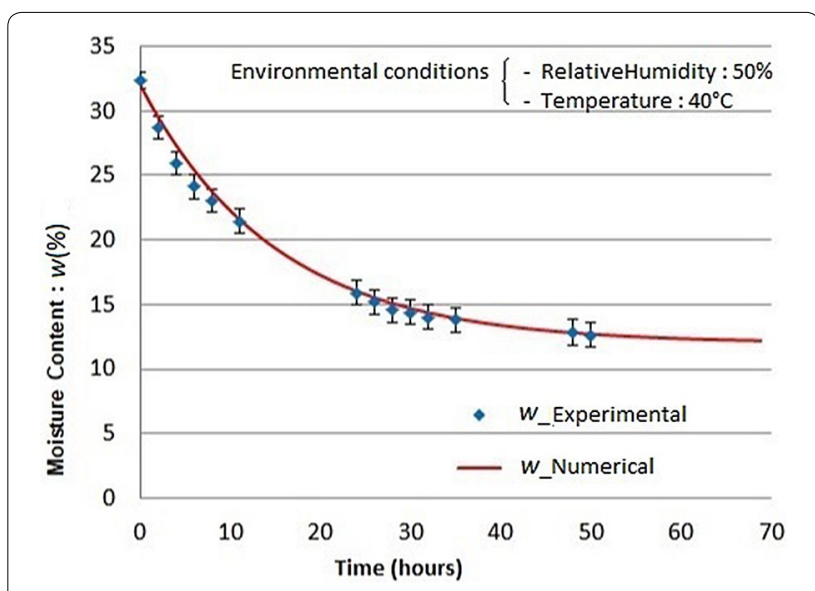

Fig. 8 Evolution of the moisture content during drying 
Table 2 Result of tangential and radial shrinkage of Bete

\begin{tabular}{lll}
\hline & Mean value (\%) & Standard deviation (\%) \\
\hline Tangential shrinkage coefficient & 0.339 & 0.022 \\
Radial shrinkage coefficient & 0.159 & 0.017 \\
\hline
\end{tabular}

$85 \%$, the mean values of diffusion coefficients of sapelli and sipo, in the radial direction, are, respectively, 6,45 $10^{-12} \mathrm{~m}^{2} / \mathrm{s}$ and $3,8210^{-12} \mathrm{~m}^{2} / \mathrm{s}$ when the moisture content varies from 22 to $27 \%$. The thickness of the samples (solid wood) was $21 \mathrm{~mm}$, for a length of $100 \mathrm{~mm}$ and a width of $30 \mathrm{~mm}$.

Therefore, significant comparisons between the diffusion coefficients of green-glued plywood and solid wood may not be easily established because the green-glued plywood is a highly heterogeneous material, compared to the solid wood. Therefore, diffusion coefficients determined in this study should be considered as reference values for further studies concerning plywood.

\section{Experimental results and numerical validation of the model}

Concerning the experimental results, Fig. 9 presents the shape of the asymmetrical green-glued plywood after $50 \mathrm{~h}$ of drying. Visible and considerable displacements of the plywood shape were observed.

The displacement $U_{\mathrm{z}}$ of the point $\mathrm{P}_{1}$ of the plywood (Fig. 9) of each sample was measured at each hour using a digital caliper and is shown in Fig. 10.

Concerning the numerical validation of these results, we remind that two scenarios were considered. The first one, we considered just the elastic and the mechanosorptive model without taking into account the viscoelastic behavior of the plywood. In the second one, that behavior was considered.

\section{Scenario 1: the visco-elastic behavior of the plywood is not considered}

Simulations were carried out. Only the change in tangential shrinkage coefficient greatly influences the displacement of the plywood sample. Variation of the tangential shrinkage coefficient $\left(\alpha_{\mathrm{T}}\right)$, starting from the data obtained in the literature for the specie Bete [15] and the experimental result, provides the evolution of the displacement at the point P1 of the plywood presented in Fig. 11 for four cases of tangential shrinkage coefficient values retained $\left(\alpha_{\mathrm{T} 1}=0.246, \alpha_{\mathrm{T} 2}=0.339, \alpha_{\mathrm{T} 3}=0.634\right.$, $\left.\alpha_{\mathrm{T} 4}=0.780\right)$.

During the first $5 \mathrm{~h}$ of drying, the displacement as a function of time is practically linear and in this range, all the coefficients of tangential shrinkage used predict well the elastic behavior of drying of the plywood. The likelihood of this scenario is limited by its ability to predict displacements in the post-elastic phase.

The value of the tangential shrinkage coefficient of the veneer is retained by minimizing the quadratic criterion between the experimental and numerical results of the first $10 \mathrm{~h}$, assuming that at this time the visco-elastic effect is negligible. This scenario's value $\left(\alpha_{\mathrm{T} 3}=0.634\right)$ differs considerably from that of solid wood. This can be justified by the presence of cracks resulting from the unwinding operation. It is therefore chosen for the rest of the numerical model.

\section{Scenario 2: the visco-elastic behavior of the plywood is considered}

The three-branched Maxwell model was considered and the parameters of viscosity $\gamma_{1}^{i}$ and $\left(\alpha_{1}^{i}\right)^{-1}$ case studied and retained are presented in Table 5.

The displacements illustrating the evolution of the plywood at the point $\mathrm{P}_{1}$ according to the variation of the viscosity parameters are shown in Fig. 12. We remind that the various displacements at the point $P_{1}$ were measured on asymmetrical plywood samples.

The visco-elastic model parameters chosen in this scenario are those corresponding to the curve $U_{\mathrm{z}-}$ Numerical_ $\alpha_{\mathrm{T} 3} \mathrm{v}_{2}$ obtained by minimizing the quadratic criterion between the experimental results to those obtained numerically. The numerical displacement field on asymmetrical samples after $50 \mathrm{~h}$ of drying is shown in Fig. 13.

Since the scenario 2 presented a more interesting ability to predict displacements in the post-elastic phase, it has been considered in the next parts of the study. The validation of the model attached to that scenario will subsequently permit to determine the deformations and the stress in the conventional plywood configuration during drying.

\section{Experimental and numerical results of the conventional configuration}

The conventional configuration corresponded to a plies' arrangement of $0^{\circ} / 90^{\circ} / 0^{\circ}$.

\section{Experimental result}

The experimental results in the same condition of drying shows that there was some surface cracking at the both sides of the plywood (Fig. 14). 


\section{Numerical results of stress fields and evolution of the stress at a plywood surface point}

The numerical results of the stress fields presented in Fig. 15 show that:

- along the X direction (aligned with the longitudinal direction of wood on the outer plies), the maximum surface stress of the plywood is in compression, corresponding to a value of $-4.3 \mathrm{MPa}$; the inner part of the plywood is in tension with a maximum value of $6 \mathrm{MPa}$.

- along the Y direction (the transverse direction of the outer plies), the surface in under tension with a maximum value of $4.4 \mathrm{MPa}$; the inner part of the plywood is under compression with a maximum stress value of - 8.6 $\mathrm{MPa}$. Tensile stress in $\mathrm{Y}$ direction which is due to the orientation of the central ply (longitudinal in $\mathrm{Y}$ direction) that prevents the deformation in $y$ direction (transversal) of the external plies, and put them in tension.

In order to understand the behavior of the stress at the surface of the plywood, the stress evolution curve of a point at the center of the plywood is plotted in the longitudinal and tangential directions. The results are illustrated by Fig. 16. The figure shows that, after five hours of drying, any stress at the surface of the plywood almost reaches its maximum value.

The numerical model provides valuable information concerning the importance of an accurate description of the green-glued plywood during drying, regarding stress, deformation and the drying kinetics.

In the conventional configuration where the plies are orthogonally arranged, the numerical results show that the stresses of the plywood, in the direction tangential to the fibers at the surface at $12 \%$ moisture content $(4.4 \mathrm{MPa})$ are greater than the average rupture stress obtained experimentally $(4.05 \mathrm{MPa})$. The accuracy of these results should make possible for plywood manufacturers to correctly plan drying programs before they are actually put into practice. In other words, the model can aid in predicting the quality (levels of shape stability and material integrity) of green-glued plywood before starting a drying program.

Concerning the drying kinetics (the evolution of the stress during drying in Fig. 16), we noted that the threshold of the maximum stress is practically reached after the first $5 \mathrm{~h}$. In other words, from 32 to $25 \%$ of water content, the stresses in the plywood are practically at their maximum. As a result, it is therefore possible for

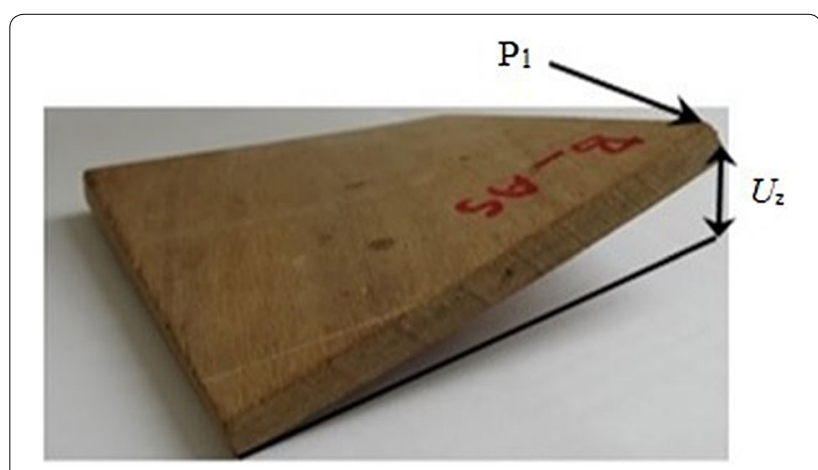

Fig. 9 Displacement of P1 obtained experimentally after $50 \mathrm{~h}$

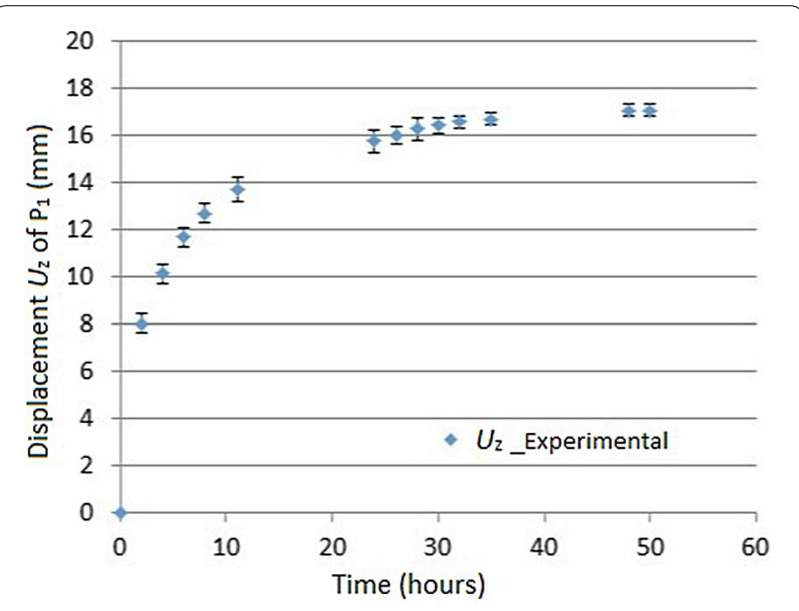

Fig. 10 Evolution of the displacement of the point $P_{1}$ of the plywood

plywood manufacturers to quantify correctly the energy savings for two drying situations. In the first one, the automatic drying program is managed until one reaches the desired moisture content. In the second one, the automatic drying program is interrupted and substituted by a natural drying of the products. In addition, some early stage measures concerning the drying program could therefore be taken if one wants to reduce the drying stress.

\section{Conclusion}

In this paper, the behavior of green-glued plywood during the drying process was simulated. A constant relative humidity $(50 \%)$ and temperature $\left(40{ }^{\circ} \mathrm{C}\right)$ were considered during drying. Small plywood specimens, manufactured by using Bete (Mansonia altissima), an abundant species from the Congo Basin, were used. 


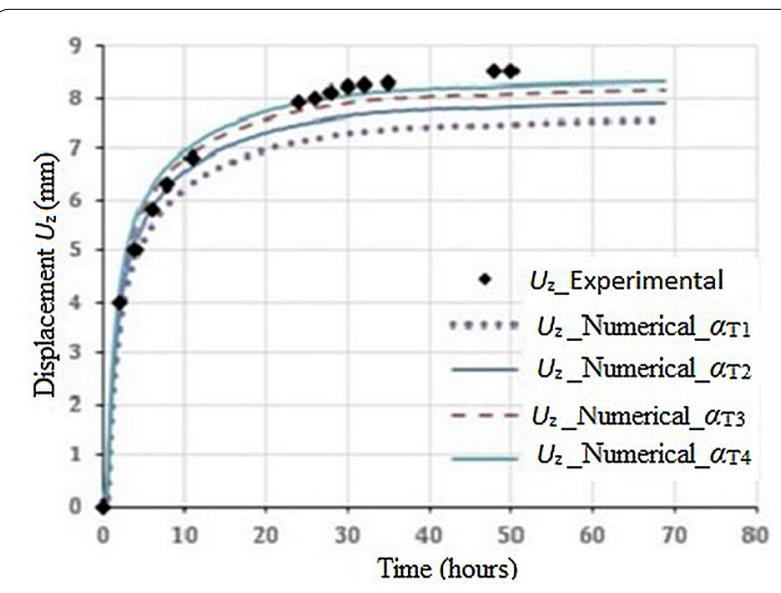

Fig. 11 Evolution of the displacement at the point $P_{1}$ of the plywood according to the variation of the tangential shrinkage (scenario 1)

Table 3 Results of tensile tests (of wood plies) longitudinal and perpendicular to fibers

\begin{tabular}{lcl}
\hline Properties & Mean (MPa) & $\begin{array}{l}\text { Standard } \\
\text { deviation } \\
\text { (MPa) }\end{array}$ \\
\hline Longitudinal MOE & 14,628 & 128 \\
Tangential MOE & 310 & 8.54 \\
RL: Ultimate stress in the RL plane & 59 & 2.16 \\
RT: Ultimate stress in the RT plane & 4,05 & 0.35 \\
\hline
\end{tabular}

Table 4 The data used in the diffusion model

\begin{tabular}{lr}
\hline Coefficient of diffusion $\left(\mathrm{m}^{2} / \mathrm{s}\right)$ & $K_{\mathrm{D}}=5.8410^{-10} \mathrm{e}^{1,97 \mathrm{w}}$ \\
Exchange coefficient $(\mathrm{m} / \mathrm{s})$ & $K_{\mathrm{C}}=2.3410^{-8}$ \\
\hline
\end{tabular}

The first step of the study focused on the experimental determination of some important material properties of the plywood and veneers, namely diffusion and exchange coefficients, tensile strength and modulus of elasticity, shrinkage coefficients and density. In the second step, the drying behavior of the plywood was quantified thanks to FEM model in which elastic, visco-elastic and mechano-sorptive aspects of the wood veneer were considered. The surface cracks in the plywood during drying are justified by the fact that the drying stress is higher than the tensile ultimate strength of the veneer. In addition, the stress at the surface of plywood reaches practically its maximum value during the first $5 \mathrm{~h}$ of drying. The simulation yields information
Table 5 Evolution and selection of the visco-elastic parameters

\begin{tabular}{lllll}
\hline $\begin{array}{l}\text { Order of } \\
\text { iteration }\end{array}$ & $\boldsymbol{\gamma}_{\mathbf{1}}^{\prime}$ & $\boldsymbol{\gamma}_{\mathbf{2}}^{\prime}$ & $\boldsymbol{\gamma}_{\mathbf{3}}^{\prime}$ & \\
\hline 1 & 0.01 & 0.015 & 0.005 & $\left(\alpha_{1}^{\prime}\right)^{-1}=0,5 \mathrm{~h}$ \\
2 & 0.05 & 0.075 & 0.025 & $\left(\alpha_{2}^{-1}=2 \mathrm{~h}\right.$ \\
3 & 0.1 & 0.15 & 0.05 & $\left(\alpha_{3}^{\prime}\right)^{-1}=10 \mathrm{~h}$ \\
\hline
\end{tabular}

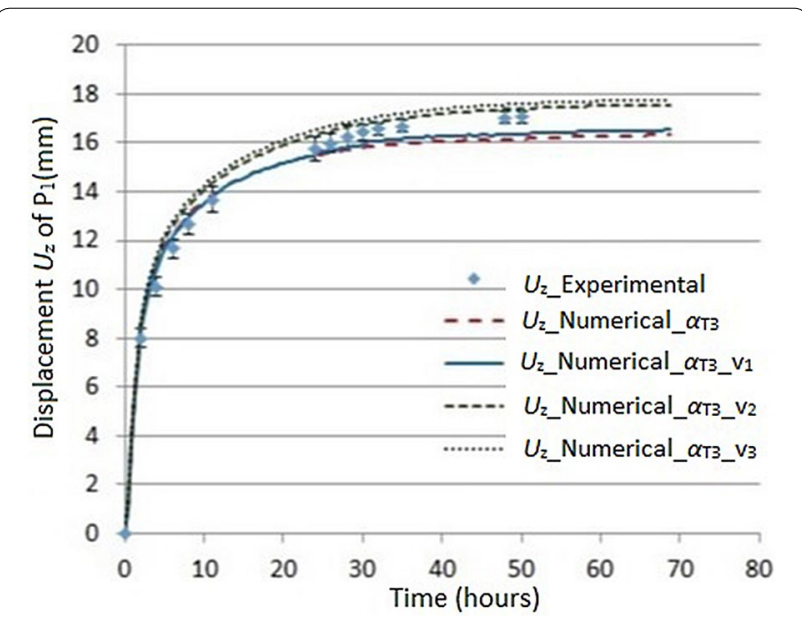

Fig. 12 Evolution of the displacement at the point $P_{1}$ of the plywood according to the variation of viscosity parameters (scenario 2)

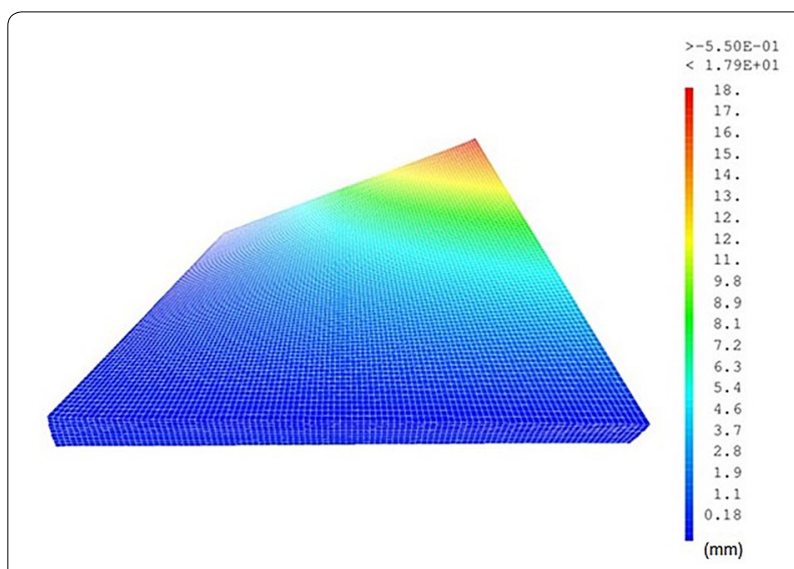

Fig. 13 Displacement field of plywood obtained numerically after 50 h of drying (scenario 2)

about unfavorable deformations and stresses during the drying process. Such information presents an interesting potential to be valuable in plywood factories, 


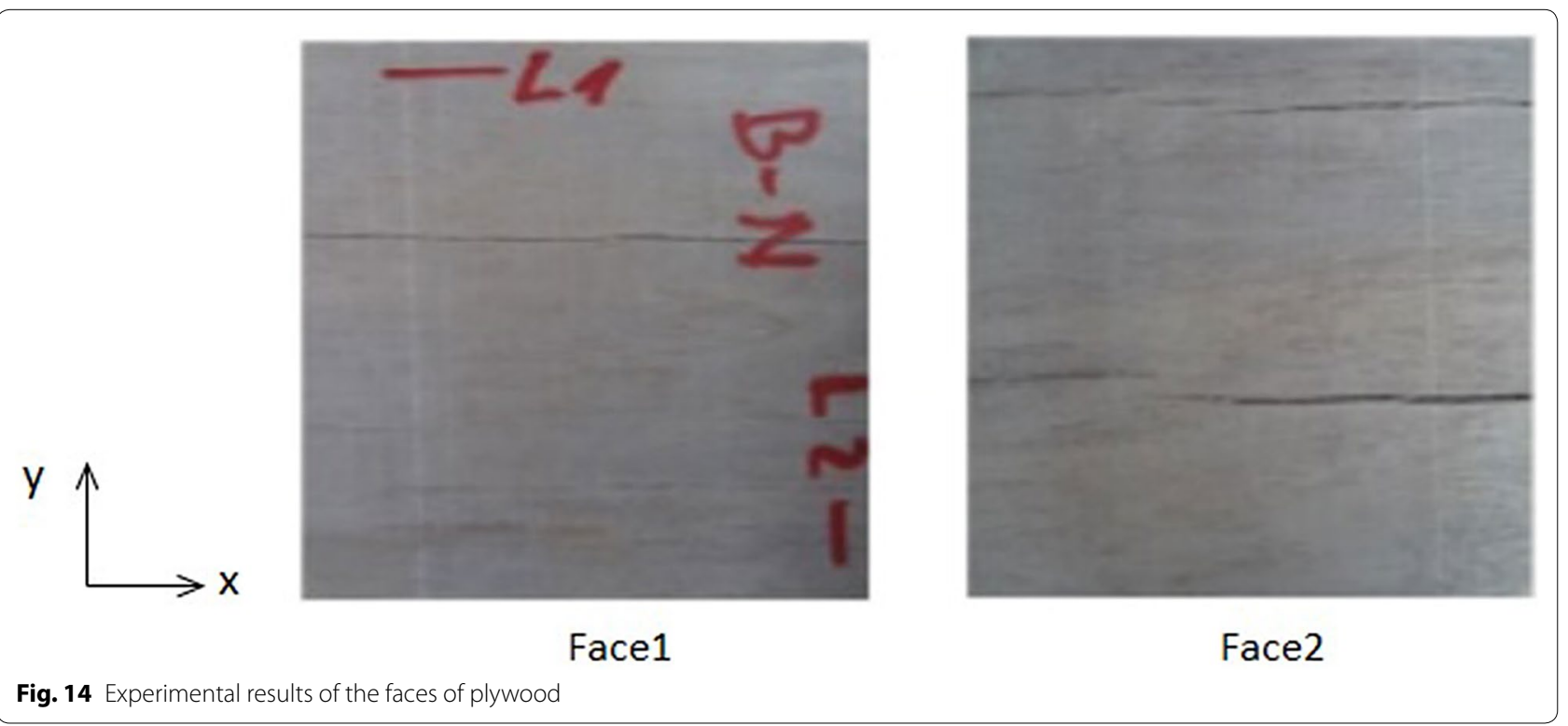

especially the quality control and the planning program of the green-glued plywood.

Further investigations will be needed in order to improve the FEM model, in the perspective to be applied on practically sized plywood according to the length and width. They concern the influence of specimen's dimensions and certain wood veneer defects on the drying behavior of the plywood and also to look for solutions at the level of the manufacturing process to improve the quality of plywood during the vacuum drying process, in particular, to reduce the cracks observed previously by relaxing the induced stress.

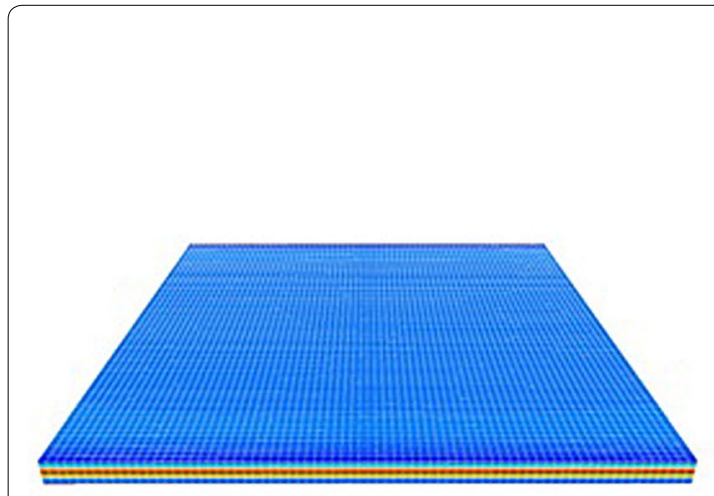

Stress Field in the $\mathrm{X}$ direction (MPa)
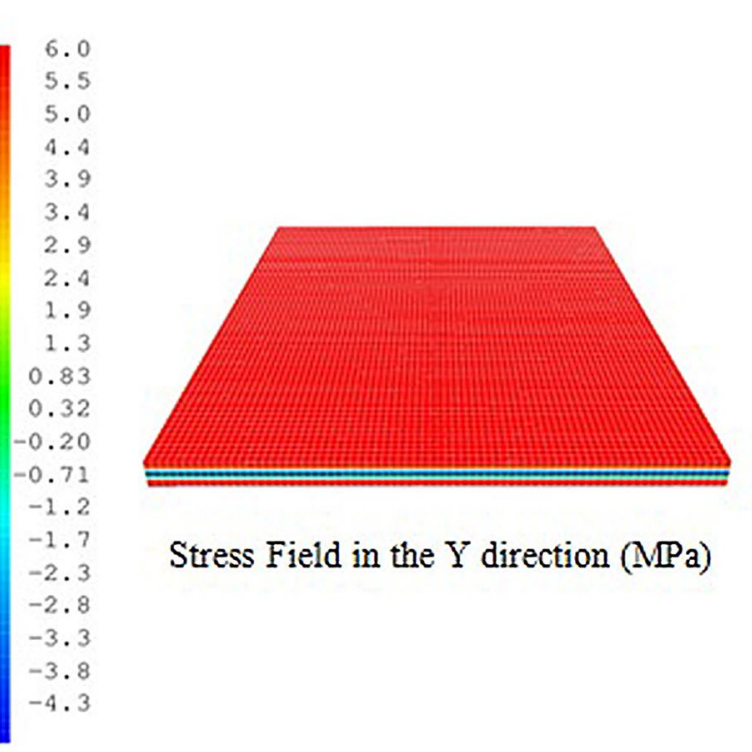

Stress Field in the $\mathrm{Y}$ direction (MPa)
4.4

3.7

3.1

2.4

1.8

1.1

0.48

$-0.18$

$-0.83$

$-1.5$

$-2.1$

$-2.8$

$-3.4$

$-4.1$

$-4.7$

$-5.4$

$-6.0$

$-6.7$

$-7.3$

$-8.0$

$-8.6$

Fig. 15 Stress fields obtained numerically after $50 \mathrm{~h}$ 


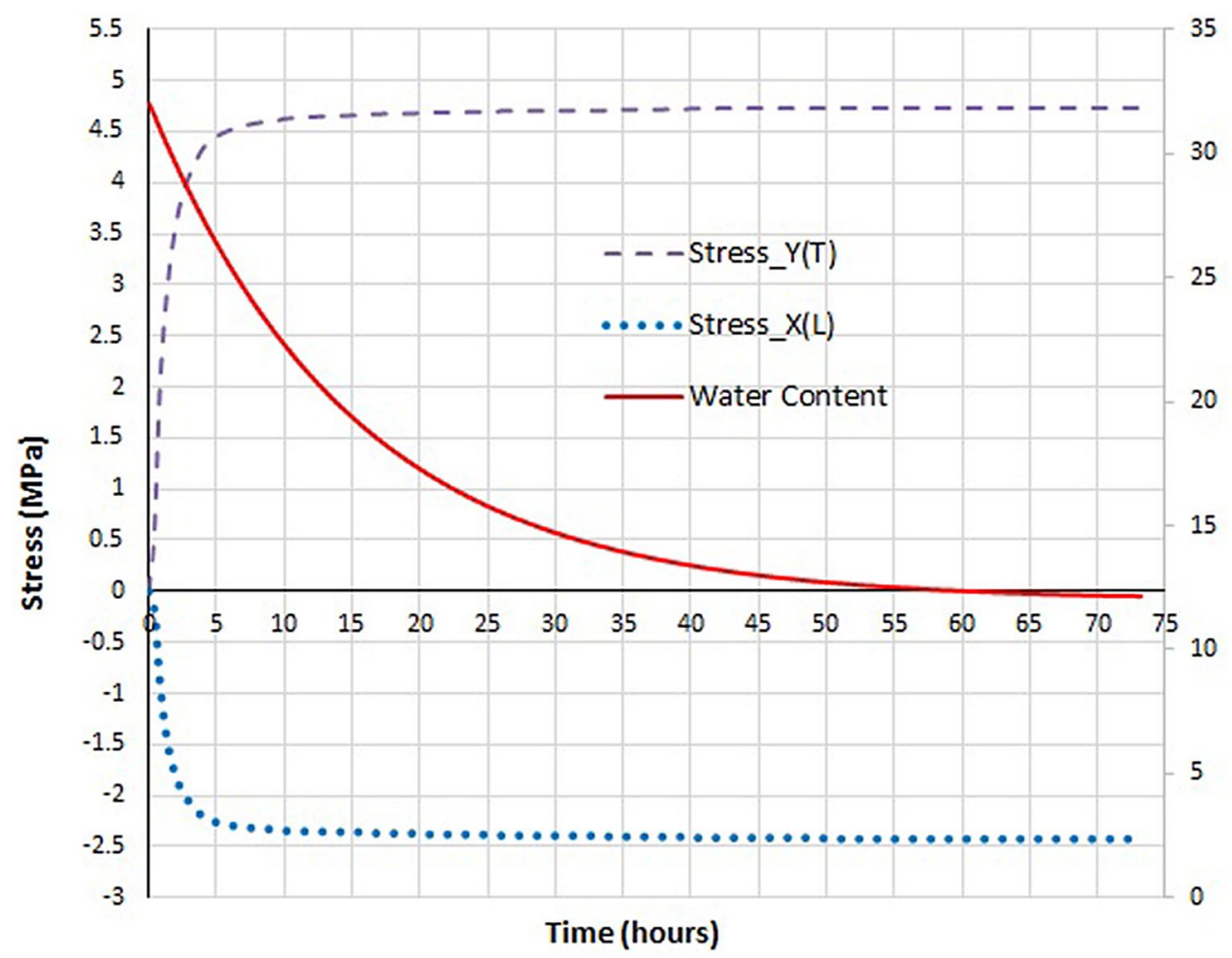

Fig. 16 Evolution of stresses in $X$ and in $Y$ at a surface point of plywood

\section{Abbreviations}

FEM: Finite element method; FSP: Fiber saturation point; CIRAD: Centre International de Recherche Agricole pour le Développement (Agricultural Research Centre for International Development), in French; MOE: Modulus of elasticity; MOR: Modulus of rupture; RH: Relative humidity.

\section{Acknowledgements}

Not applicable.

\section{Authors' contributions}

$M V$, PR and LD had elaborated the experimental drying of plywood. MV, PR, PA, $\mathrm{OR}$, and $\mathrm{BD}$ had simulated numerically the plywood glued at the green state. $\mathrm{MV}, \mathrm{PR}$ and $\mathrm{OR}$ and $\mathrm{DB}$ analyzed and interpreted the drying curve. All authors read and approved the final manuscript.

\section{Funding}

All sources of funding for the research are from the University of Bordeaux (Grant No. +237677321544)

\section{Availability of data and materials}

The datasets used and/or analyzed during the current study are available from the corresponding author on reasonable request.

\section{Competing interests}

The authors declare that they have no competing interests.

\section{Author details}

1 Univ. Bordeaux, I2M, UMR 5295, 351 cours de la Libération, 33400 Talence, France. ${ }^{2}$ The University Institute of Wood Technology, The University of Yaounde I, P.O. Box 306, Mbalmayo, Cameroon. ${ }^{3}$ Laboratory of Civil
Engineering and Mechanics, National Advanced School of Engineering, The University of Yaounde I, P.O. Box 8392, Yaounde, Cameroon. ${ }^{4}$ LaBoMaP, Laboratory of Material and Process of Bourgogne, ENSAM Cluny, 1 rue Porte de Paris, 71250 Cluny, France.

Received: 23 August 2019 Accepted: 7 September 2020

Published online: 01 October 2020

\section{References}

1. Villiere A (1964) Le séchage des placages dans l'industrie du contreplaqué (Veneer drying in the plywood industry, in French). Rev Bois Forêts Tropi, 96 : 27-29. https://revues.cirad.fr/index.php/BFT/issue/view/18917.

2. Clouet B, Pommier R, Danis M (2014) New composite timbers: Full-field analysis of adhesive behavior. J Strain Anal Eng Des 49(3):155-160. https ://doi.org/10.1177/0309324713486894

3. Oum Lissouck R, Pommier R, Taillandier F, Mvogo J, Breysse D, Ayina Ohandja LM (2018) A decision support tool approach based on the Electre TRI-B method for the valorisation of tropical timbers from the Congo Basin: an application for glulam products. Southern Forests 80(4):361371. https://doi.org/10.2989/20702620.2018.1463153

4. Glavin RE (1946) Molding and gluing press. US Patent 2,401,299, 4 Jun 1946.

5. Heebink BG (1953) Fluid pressure molding of plywood. US For Prod Lab Rep, No. R1624, Madison 5, Wisc.

6. Ngo D, Pfeiffer E (2003) The art of plywood furniture. Prin Architec Press, New York, p 144

7. Pommier R, Grimaud G, Princaud M, Perry N (2016) LCA (Life Cycle Assessment) of EVP-Engineering veneer product: plywood glued using a vacuum moulding technology from green veneers. J clean Prod 124:383-394. https://doi.org/10.1016/j.jclepro.2016.02.130 
8. Lavalette A, Cointe A, Pommier R, Danis M, Delisee C, Legrand G (2016) Experimental design to determine the manufacturing parameters of a green-glued plywood panel. Eur J Wood Prod 74:543-551. https://doi. org/10.1007/s00107-016-1015-4

9. EN 314-1 (2004) Contreplaqué Qualité du Collage. Part 1: méthode d'essai (Plywood Bonding quality. Part 1 : Test Method, in French).

10. Ormarsson S, Dahlblom O, Petersson H (1999) A numerical study of the shape stability of sawn timber subjected to moisture variation. Wood Sci Technol 33(5):407-423

11. Moutee M (2006) Modélisation du Comportement mécanique du bois au cours du séchage (Modeling the mechanical behavior of wood during drying, in French). Univ Laval, Canada, Thesis

12. GEREKET, (2009) Moisture-induced stresses in cross-laminated wood panels. Eidgenössische Technische Hochschule Zürich, Degree Doct Sci, p 192

13. Martensson A (1992) Mechanical behavior of Wood exposed to humidity variations. Dep Struct Engin, Rep TVBK-1006, Lund University.

14. Sung-Lam N, Destrebecq JF (2015) Modèle incremental à pas de temps fini pour la simulation du comportement hydromécanique du bois (Incremental model with finite time step for the simulation of the hygromechanical behavior of wood, in French). In : Proceedings of the $33^{\text {rd }}$ meeting of the French Association of Civil Engineering, University of Pau, Bayonne, 27-29 May 2015.

15. FAO (Food and Agriculture Organization of the United Nations) (2006) Global forest resources assessment 2005: progress towards sustainable forest management. FAO Forestry Paper. Rome: FAO.

16. CIRAD (Agricultural Research Centre for International Development, in French)(2014) Tropix 7.0 : Synthèse des caractéristiques technologiques de 245 essences tropicales (Synthesis of the technological characteristics of 245 tropical species, in French). https://doi.org/10.18167/74726F7069 78.

17. NF EN 326-1 (1994) NF EN 326-1 (1994) Panneaux à base de bois, échantillonnage, découpe contrôle. Partie l: échantillonnage, découpe des éprouvettes et expression des résultats d'essai (Wood-based panels Sampling, cutting and checking. Part 1: sampling, cutting of test samples and expression of results, in French)

18. Morlier P, De Jeso B, Daude G, Dimier G (2002) Composition adhésive pour matériau humide (Adhesive composition for wet material). (In French), Patent 2842818.

19. Yeo H, Smith WB, Hanna RB (2002) Mass transfer in wood evaluated with a calorimetric technique and numerical analysis. Wood Fiber Sci 34(3):419-424

20. Yeo H, Smith WB, Hanna RB (2002) Determination of surface moisture content of wood utilizing a colorimetric technique. Wood and F'ieber Sci 34(4):419-424
21. Merakeb S (2006) Modélisation des structures en bois en environnement variable (Modeling of wood structure under variable climate, in French). Doctoral thesis. University of Limoges, p.146.

22. Guitard D, El Amri F (1984) Modèles prévisionnels de comportement élastique tridimensionnels pour les bois feuillus et les bois résineux (Three-dimensional elastic behavior predictive models for hardwoods and sofwoods, in French). An sci fores, INRA/EDP Sci 44(3):335-358

23. Santaoja K, Leino T, Ranta-Maunus A (1991) Mechano-sorptive structural analysis of wood by the ABAQUS finite element program. Tech Res Cen Fin, Res notes 1276, Espoo.

24. Henderson S M (1974) Progress in Developing the Thin Layer Drying Equation. Transactions of the ASAE, 17, 1167-1168. dx.doi. org/10.13031/2013.37052

25. Tremblay C, Cloutier A, Fortin Y (2000) Experimental determination of the convective heat and mass transfer coefficients for wood drying. Wood SCi Techno 34(3):253-276

26. Perré $P$, Agoua E (2010) Mass transfer on wood: identification of structural parameters from diffusivity and permeability measurements. J Por Med 13(11):1017-1024

27. Simo-Tagne M, Rémond R, Rogaune $Y$, Zoulalian A, Bonoma B (2016) Sorption behavior of four tropical woods using a dynamic vapor standard analysis system. Maderas : Ciencia y Tecnologia 18(3):2006. https://doi. org/10.4067/S0718-221X2016005000036

28. Nsouandele JL, Tamba JG, Bonoma B (2010) Desorption isotherms of heavy (AZOBE, EBONY) and light heavyweight tropical woods (IROKO, SAPELLI) of Cameroon. Heat Mass Transf 54:3089-3096. https://doi. org/10.1007/s00231-018-2350-2

29. Simo Tagne M (2019) Modeling, numerical simulation and validation of a convective dryer in steady conditions: case study of tropical woods. Int J Modelling Simulation. https://doi.org/10.1080/02286203.2019.1575111

30. Oum Lissouck R, Pommier R, Breysse D, Ayina Ohandja LM, Mansié DA, R, (2016) Clustering for preservation of endangered timber species from the Congo Basin. J of Trop For Sci 28:4-20

31. Mukudai J, Yata S (1986) Modeling and simulation of viscoelastic behavior (tensile strain) of wood under moisture change. Wood Sci Technol 20:335-348

\section{Publisher's Note}

Springer Nature remains neutral with regard to jurisdictional claims in published maps and institutional affiliations.

\section{Submit your manuscript to a SpringerOpen ${ }^{\circ}$ journal and benefit from:}

- Convenient online submission

- Rigorous peer review

- Open access: articles freely available online

- High visibility within the field

- Retaining the copyright to your article

Submit your next manuscript at springeropen.com 